Basic Science

\title{
e Cytotoxic Effect of Commercially Available Methylprednisolone Acetate with and without Reduced Preservatives on Dorsal Root Ganglion Sensory Neurons in Rats
}

Nebojsa Nick Knezevic, MD, PhD ${ }^{1,2}$, Kenneth D. Candido, $\mathrm{MD}^{1,2}$, Ivan Cokic, $\mathrm{MD}^{3}$, Aleksandar Krbanjevic, MD, PhD ${ }^{4}$, Sarah L. Berth, BS ${ }^{5}$, and Ivana Knezevic, MD ${ }^{1,6}$

From: ${ }^{2}$ Department of Anesthesiology, Advocate Illinois Masonic Medical Center, Chicago, IL; ${ }^{2}$ Department of Anesthesiology, University of Illinois, Chicago, IL; '3Biomedical Imaging Research Institute, Cedars-Sinai Medical Center, Los Angeles, CA; ${ }^{\text {Department }}$ of Pharmacology, University of Illinois, Chicago, IL; 5Department of Anatomy and Cell Biology, University of Illinois, Chicago, IL;

${ }^{6}$ Department of Physiology and Biophysics, University of Illinois, Chicago, IL

Additional Author Affiliation Information on P. E617.

Corresponding Author: Nebojsa N. Knezevic, MD, PhD Department of Anesthesiology Advocate Illinois Masonic Medical Center $836 \mathrm{~W}$. Wellington Ave. Suite 4815

Chicago, IL 60657 E-mail:

nick.knezevic@gmail.com

Disclaimer: There was no external funding in the preparation of this manuscript. Conflict of interest: Each author certifies that he or she, or a member of his or her immediate family, has no commercial association (i.e., consultancies, stock ownership, equity interest, patent/licensing arrangements, etc.) that might pose a conflict of interest in connection with the submitted manuscript.

Manuscript received: 02-21-2014

Revised manuscript received: 03-31-2014

Accepted for publication: 04-24-2014

Free full manuscript: www.painphysicianjournal.com
Background: Epidural and intrathecal injections of methylprednisolone acetate (MPA) have become the most commonly performed interventional procedures in the United States and worldwide in the last 2 decades. However neuraxial MPA injection has been dogged by controversy regarding the presence of different additives used in commercially prepared glucocorticoids. We previously showed that MPA could be rendered $85 \%$ free of polyethylene glycol (PEG) by a simple physical separation of elements in the suspension.

Objective: The objective of the present study was to explore a possible cytotoxic effect of commercially available MPA (with intact or reduced preservatives) on rat sensory neurons.

Methods: We exposed primary dissociated rat dorsal root ganglia (DRG) sensory neurons to commercially available MPA for 24 hours with either the standard (commercial) concentration of preservatives or to different fractions following separation (MPA suspension whose preservative concentration had been reduced, or fractions containing higher concentrations of preservatives). Cells were stained with the TUNEL assay kit to detect apoptotic cells and images were taken on the Bio-Rad Laser Sharp-2000 system. We also detected expression of caspase-3, as an indicator of apoptosis in cell lysates.

Results: We exposed sensory neurons from rat DRG to different concentrations of MPA from the original commercially prepared vial. TUNEL assay showed dose-related responses and increased percentages of apoptotic cells with increasing concentrations of MPA. Increased concentrations of MPA caused $1.5-2$ times higher caspase-3 expression in DRG sensory neurons than in control cells (ANOVA, $P=0.001$ ). Our results showed that MPA with reduced preservatives caused significantly less apoptosis observed with TUNEL assay labeling $(P<0.001)$ and caspase- 3 immunoblotting $(P$ $\leq 0.001)$ than in neurons exposed to MPA from a commercially prepared vial or "clear phase" that contained higher concentrations of preservatives. Even though MPA with reduced preservatives caused $12.5 \%$ more apoptosis in DRG sensory neurons than in control cells, post hoc analysis showed no differences between these 2 groups.

Limitations: Our data was collected from in vitro isolated rat DRG neurons. There is a possibility that in vivo neurons have different extents of vulnerability compared to isolated neurons.

Conclusions: Results of the present study identified a cytotoxic effect of commercially available MPA with preservatives or with a "clear phase" containing higher concentrations of preservatives on primary isolated rat DRG sensory neurons. This was shown by TUNEL positive assay and by increased caspase-3 expression as one of the final executing steps in apoptotic pathways in DRG neurons. However, our results showed no statistically significant difference between the control cells (salinetreated) and cells treated with MPA with reduced concentrations of preservatives, pointing out that either PEG or myristylgamma-picolinium chloride (MGPC) or their combination have harmful effects on these cells. Reduction of concentrations of preservatives from commercially available MPA suspensions by using the simple method of inverting vials for 2 hours could be considered useful in clinical practice to enhance the safety of this depot steroid when injected neuraxially.

Key words: Methylprednisolone acetate, preservatives, dorsal root ganglion sensory neurons, cytotoxic effect, polyethylene glycol, myristylgamma-picolinium chloride

Pain Physician 2014; 17:E309-E318 


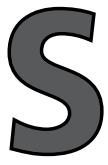

ince the first published reports of methylprednisolone acetate (MPA) injection into the epidural space for treating radicular pain in 1960 (1) and the first prospective study by Winnie et al in 1972 (2), wherein the authors compared epidural and intrathecal injections of MPA, MPA injections have become the most commonly performed interventional procedures in the United States and worldwide in the last 2 decades (3-6). However neuraxial MPA injection has been dogged by controversy, and neither the US Food and Drug Administration (FDA) nor manufacturers advocate intrathecal or epidural administration of MPA (7-9).

One area of controversy is the presence of different additives to commercially prepared glucocorticoids: benzyl alcohol, benzalkonium chloride, myristylgamma-picolinium chloride (MGPC), or polyethylene glycol (PEG). Benzyl alcohol was removed by the manufacturer from single dose vials ( $1 \mathrm{~mL})$ of MPA and was replaced with MGPC in 1991 (10). MPA suspension for single-use (Depo-Medrol®, Pharmacia \& Upjohn Company, Kalamazoo, Ml; $80 \mathrm{mg} / \mathrm{mL}$ ) contains an alcohol and nonionic detergent, PEG (2.82\%) and a bacteriostatic agent MGPC $(0.0189 \%)$. However, even the vial with the half dose of MPA (40 mg/mL) contains almost the same concentration of both PEG (2.91\%) and MGPC (0.0195\%).

While the use of MPA with or without preservatives has long been an intriguing topic, there has been renewed interest in this issue following the publication in October 2012 in the New England Journal of Medicine detailing the index case of fungal spinal meningitis associated with tainted, compounded MPA injected into the epidural space $(11,12)$. Based on the October 23, 2013, update from the Centers for Disease Control and Prevention, there have been 751 reported cases of fungal meningitis in 20 states including 64 deaths following spinal injection of contaminated MPA (New England Compounding Center, Framingham, MA) (13). The use of compounded MPA requires extra precautions for its preparation, primarily due to the possibility of bacterial or fungal contamination. The compounding of MPA has essentially been undertaken for 2 purposes; to remove MGPC and PEG in an attempt to minimize the theoretical risk of arachnoiditis associated with neuraxial steroids, and to reduce costs associated with the purchase of the commercial product. However, the recent meningitis outbreak associated with compounded MPA highlighted the potential risks of using noncommercial medications wherein product preparation was not subjected to the rigors of industry standards and oversight.
We recognized the usefulness of identifying a preservative-free, commercially prepared form of MPA and we previously reported that approximately $85 \%$ of PEG could be removed from an MPA suspension by keeping commercially prepared MPA vials inverted for more than 2 hours and by subsequently aspirating only the steroid component from the vial (14). We have not measured concentrations of MGPC (14), but Rijsdijk et al (15) showed that centrifugation of MPA vials reduced the concentration of MGPC by as much as 15 times. We are assuming that the vial inversion will reduce concentrations of both preservatives PEG and MGPC as well. Rijsdijk et al (15) estimated without actually measuring PEG that the concentration of PEG would theoretically be approximately 0.1 times the reported manufacturer's concentration. Furthermore, they showed that the intrathecal (IT) administration of MPA in a canine model may be harmful to the spinal cord (15).

Thus, to explore a possible cytotoxic effect of commercially available MPA (with intact or reduced preservatives) on rat sensory neurons, we exposed the primary dissociated neurons of the rat dorsal root ganglia (DRG) to commercially available MPA, with either the standard commercial concentration of preservatives left intact, or to one of the 2 phases separated after using our previously described technique (14) (MPA whose preservative concentration had been reduced or phase containing mainly preservatives).

\section{Methods}

\section{Isolation and culture of the primary sensory neurons from rat DRG.}

All experiments involving animals were conducted according to protocols approved by the Institutional Animal Care and Use Committee at University of Illinois-Chicago. Sensory neurons were isolated from the rat DRG according to previously published protocols (16-18). Dissecting instruments were sterilized in an autoclave for 15 minutes and left to cool. SpragueDawley rat pups 3 - 10 days old (Harlan Laboratories, Indianapolis, IN) were euthanized by $\mathrm{CO} 2$ asphyxiation and taken under sterile conditions into a tissue culture hood, where we poured $10 \mathrm{~mL}$ of sterile Hank's Balanced Salt Solution (HBSS) (Gibco, San Diego, CA) in 100 $\mathrm{mm}$ tissue culture plate and placed on ice. Rats were dissected under a microscope at magnification of 1.5X. The ventral part of the spinal column was located with forceps and transferred into a new plate containing HBSS. DRGs were carefully cleaned from extraneous tis- 
sue under the microscope and immersed in sterile HBSS. Using a coated glass pipette and $0.1 \%$ Bovine Serum Albumin/Phosphate Buffered Saline (BSA/PBS) (Fisher, Waltham, MA) DRGs were collected, left to settle on the bottom of the pipette for 20 seconds and transferred into a $15 \mathrm{~mL}$ conical tube containing $0.25 \%$ trypsin (Invitrogen, San Diego, CA) in HBSS. Enzymatic dissociation was done by incubation in a $37^{\circ} \mathrm{C}$ water bath for up to 20 minutes. Following incubation, trypsin was inactivated by adding $10 \%$ fetal bovine serum (FBS), and the tube was centrifuged for 6 minutes at $600 \mathrm{~g}$. The supernatant was aspirated and cell pellets were re-suspended in $1 \mathrm{~mL}$ serum-free Neurobasal medium (Invitrogen, San Diego, CA), supplemented with 2\% B27 (Invitrogen), 1\% Glutamax (Invitrogen), 0.5\% penicillin/ streptomycin $(10,000 \mathrm{U} / \mathrm{mL}$ each, Invitrogen), and $2.5 \mathrm{~S}$ Nerve Growth Factor ( $20 \mathrm{ng} / \mathrm{mL}$, Invitrogen). DRG neurons were counted and plated in desired densities. Cells were kept in a $37^{\circ} \mathrm{C}, 5 \% \mathrm{CO} 2$ humidified atmosphere and the medium was changed by half, every other day. Ten $\mu \mathrm{l}$ 5-Fluoro-2'-dexyuridine (FudR) was added to the cell media every other time the media was replaced to eliminate non-neuronal cells.

Glass cover slips were prepared prior to seeding, when cover slips first are immersed in concentrated nitric acid and rinsed with water, then flame sterilized with $70 \%$ ethanol. For coating, $0.5 \mathrm{mg} / \mathrm{mL}$ of poly-L-lysine (Invitrogen, San Diego, CA) was prepared in autoclaved deionized water. Sterile cover slips and 12-well plates (CorningCostar, Sigma-Aldrich, St. Louis, MO) covered with coating solution were incubated overnight (or longer) at room temperature. After that, poly-L-lysine was removed and cover slips and 12-well plates were rinsed with autoclaved deionized water 4 times for half an hour each. Next, $10 \mu \mathrm{g} / \mathrm{mL}$ laminin (Sigma-Aldrich, St. Louis, $\mathrm{MO}$ ) in HBSS was spread over and incubated for additional 24 hours. Such coated glass cover slips and 12-well plates were used for plating sensory neurons from DRG.

\section{Treatment of rat DRG sensory neurons.}

Sensory neurons were left to differentiate on the poly-L-lysine coated cover slips and 12-well plates for 10 days at $37^{\circ} \mathrm{C}$ in $5 \% \mathrm{CO} 2$ incubator. Two sets of experiments were performed. In the first set of experiments, cells were exposed to different concentrations of commercially available MPA $(0,10,20$, and $40 \mathrm{ng} / \mathrm{mL})$ dissolved in the normal saline solution (NSS). In the second set of experiments, we analyzed 4 experimental groups, using $20 \mathrm{ng} / \mathrm{mL}$ concentration: control group - exposed to normal saline solution; cells treated with only "white phase" (containing reduced concentration of preservatives); cells treated with only "clear phase" containing mainly preservatives; and cells treated with original mixed solution (commercially available MPA with preservatives). Briefly, commercially available MPA formulation vial (Depo-Medrol ${ }^{\circledR}$, Pharmacia \& Upjohn Company, Kalamazoo, Ml; $80 \mathrm{mg} / \mathrm{mL}$ ) was used to aspirate $100 \mu \mathrm{L}$ of original MPA solution (mixed phase). The vial with the remaining $900 \mu \mathrm{L}$ of the original solution was inverted for 2 hours to promote partition of the PEG component away from the steroid component. While keeping the vial inverted, a $3 \mathrm{~mL}$ syringe with an 18-gauge blunt tipped needle was gently inserted into the vial through the sealed rubber stopper and aspiration of only the steroid precipitate (white) phase (MPA with reduced concentration of preservatives) was undertaken. Another syringe and needle were used to aspirate the remaining upper solvent phase (containing higher concentrations of preservatives).MPA from the original vial, as well as two separated phases, were diluted in NSS and added into $1 \mathrm{~mL}$ of neuronal maintenance media per well (12-well plate) to obtain final concentration. The treatment of sensory neurons was pursued in a 5\% CO2 atmosphere in an incubator at $370 \mathrm{C}$ for 24 hours in serum-free medium. We used much smaller concentrations of MPA than those used clinically in humans for epidural injections $(80 \mathrm{mg})$, because we used bare DRG neurons without other protective cells such as microglia, astrocytes, fat cells inside dural nerve root sleeves, epidural fat cells, etc.

\section{TUNEL staining (Terminal deoxynucleotidyl transferase dUTP nick end labeling).}

TUNEL assay is a method for detecting DNA fragmentation by labeling the terminal free ends of nucleic acids. The DNA strand brakes are direct consequence of apoptosis activation. The DRG sensory neurons were treated with freshly prepared MPA solutions and control solution (as described above) for 24 hours. Thereafter, neurons were stained with the TUNEL assay kit (In Situ Cell Death Detection Kit, POD, Roche, Mannheim, Germany) as per manufacturer's instructions (19). Briefly, following the treatment, neurons were fixed in freshly prepared $4 \%$ paraformaldehyde dissolved in PBS ( $\mathrm{pH}$ 7.4) for 30 minutes at room temperature, than washed with pure PBS. Neurons were then incubated in permeabilisation solution $(0.1 \%$ Triton X-100 in $0.1 \%$ sodium citrate [Fisher, Waltham, MA]) $\mathrm{pH} 6.0$ for an additional 2 minutes. TUNEL labeling reaction mixture was prepared immediately prior 
to use, by mixing $50 \mu \mathrm{L}$ of enzyme solution to the 450 $\mu \mathrm{L}$ labeling solution (vial 2 ) and stored on ice. After a brief wash in pure PBS, neurons were incubated in 50 $\mu \mathrm{L}$ of the mixture per cover slip, for an hour at $37^{\circ} \mathrm{C}$ in an incubator, to allow a green fluorescence signal to develop. Two negative controls per each experiment were included by incubating cells cover slips in labeling solution only. Before mounting with Prolong Antifade reagent (Molecular probes, San Diego, CA), cells cover slips were washed 3 times with PBS. In the last wash, 10 $\mu \mathrm{L}$ of nuclear ToPro (Molecular Probes, San Diego, CA) dye reagent was added per $3 \mathrm{~mL}$ PBS and spread over the neurons for 10 minutes for nuclear stain to develop.

For quantification, 10 fields from each cover slip were randomly selected per each treatment condition. The experiment was repeated 2 more times, and the total number of fields used was 30 per each treatment. The TUNEL positive cells (green labeled cells) in the cell monolayer were counted versus viable cells (blue labeled cells nuclei) identified by nuclear ToPro staining. The ratio of the number of apoptotic sensory neurons to the total number of sensory DRG neurons was calculated. The cell type was scored using the Cell Counter plug-in of Image J software (NIH). Imaging was performed on the Bio-Rad Laser Sharp 2000 system (Bio-Rad, Hercules, CA) using 40x objective (Zeiss, Oberkochen, Germany).

\section{Caspase-3 Western blotting assay.}

After 24 hours of DRG sensory neurons stimulation, cells were washed, collected, and lysed in detergent lysis buffer $(20,21)$ containing $50 \mathrm{mmol} / \mathrm{l}$ Tris- $\mathrm{HCl}, \mathrm{pH} 7.4,150$ $\mathrm{mmol} / \mathrm{l} \mathrm{NaCl}, 1 \mathrm{mmol} / \mathrm{l}$ EDTA $1 \%$ Triton X-100, $1 \mathrm{mmol} / \mathrm{l}$ phenylmethylsulfonyl fluoride, $1 \mathrm{\mu g} / \mathrm{ml}$ leupeptin, and 1 $\mu \mathrm{g} / \mathrm{ml}$ aprotinin. The lysates were centrifuged at 14,000 rpm for 20 minutes at $4^{\circ} \mathrm{C}$, and protein concentrations were measured using bicinchoninic acid (BCA) protein assay reagent (Pierce, Rockford, IL) with BSA as standard. Protein from lysates were separated by loading $40 \mu \mathrm{g}$ of total protein on $12.5 \%$ reducing SDS-PAGE gel and transferred by electrophoreses to polyvinylidine fluoride membranes (Bio-Rad Laboratories, Hercules, CA). Membranes were blocked with Tween-20-Trisbuffered saline (10-mmol/l Tris- $\mathrm{HCl}, \mathrm{pH} 7.5,100 \mathrm{mmol} / \mathrm{l}$ $\mathrm{NaC1}$, and $0.1 \%$ Tween 20 ) containing $5 \%$ nonfat dry milk (Bio-Rad) for one hour before incubation with either primary anti-caspase 3 antibody 1:100 (Amersham Pharmacia, Biotech, NJ) or actin antibody 1:1,000 (Santa Cruz Biotechnology, CA). Antigen detection was performed by Amersham ECL prime western blot detec- tion kit (GE Healthcare Life Sciences, Buckinghamshire, UK) with horseradish peroxidase conjugated secondary antibodies. Membranes were exposed to film (Kodak, Rochester, NY), scanned, and densities were determined by Bio-Rad multi imager. Expression of proteins was corrected for actin control, and signal intensity analysis was performed by using Image J program (NIH).

Statistical analysis was performed using SPSS software (IBM SPSS Statistics 20, Chicago, IL). Differences in percentages of apoptotic cells and differences in caspase-3 expression between 4 different doses in the first set of experiments and between 4 different groups in the second set of experiments were analyzed using one-way Analysis of Variance (ANOVA) test. In order to distinguish differences between paired groups we used Bonferroni post hoc analysis. A $P$ value less than 0.05 was considered to be statistically significant.

\section{Results}

In the first set of experiments we exposed primary neuronal cells (sensory neurons from rat DRG) to different concentrations of MPA $(0,10,20$, and $40 \mathrm{ng} / \mathrm{mL})$ from the original commercially prepared vial (Depo-Medrol ${ }^{\circledR}$, $80 \mathrm{mg} / \mathrm{ml}$ MPA, Upjohn Pharmaceuticals, Kalamazoo, Michigan). TUNEL assay showed dose-related responses and increased percentages of apoptotic cells with increasing concentrations of MPA (Fig. 1 A, B). All tested concentrations of commercially available MPA caused 2 - 2.5 times more apoptotic cells than control (salinetreated) cells (ANOVA, $P<0.0001$ ) (Fig. 1B). However, post hoc analysis between different doses showed no statistical difference between adjacent doses (between 10 and $20 \mathrm{ng} / \mathrm{mL} P=0.385$; between 20 and $40 \mathrm{ng} / \mathrm{mL} P$ $=0.464)$. Only the difference between 10 and $40 \mathrm{ng} / \mathrm{mL}$ was statistically significant ( $P=0.03$ ) (Fig. 1B).

Caspase-3 expression showed similar results (Fig. 2 A, B). Increased concentrations of commercially available MPA caused 1.5 - 2 times higher caspase-3 expression in DRG sensory neurons than in control (salinetreated) cells (ANOVA, $P=0.001$ ) (Fig. 2B). However, post hoc analysis showed no statistically significant difference between paired groups $(P>0.05)$.

In order to clarify the cytotoxic effect of MPA with intact or reduced preservatives, we exposed DRG sensory neurons to MPA from the original commercially prepared vial, or to one of the 2 separated phases. Our results showed that MPA with reduced preservatives caused significantly less apoptosis observed with TUNEL assay labeling $(P<0.001)$ (Fig. 3$)$ and caspase-3 immunoblotting $(P \leq 0.001)$ (Fig. 4) than neurons exposed 


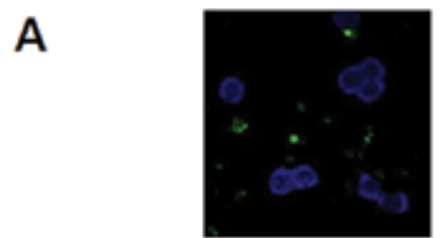

$\operatorname{MPA}(\mathrm{ng} / \mathrm{ml}) \quad 0$

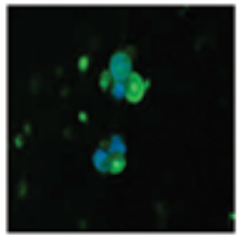

10

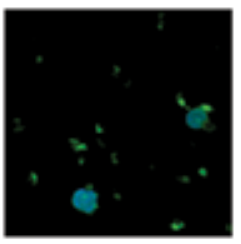

20

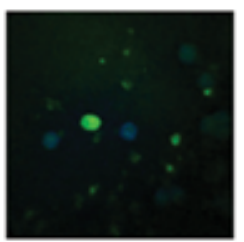

40

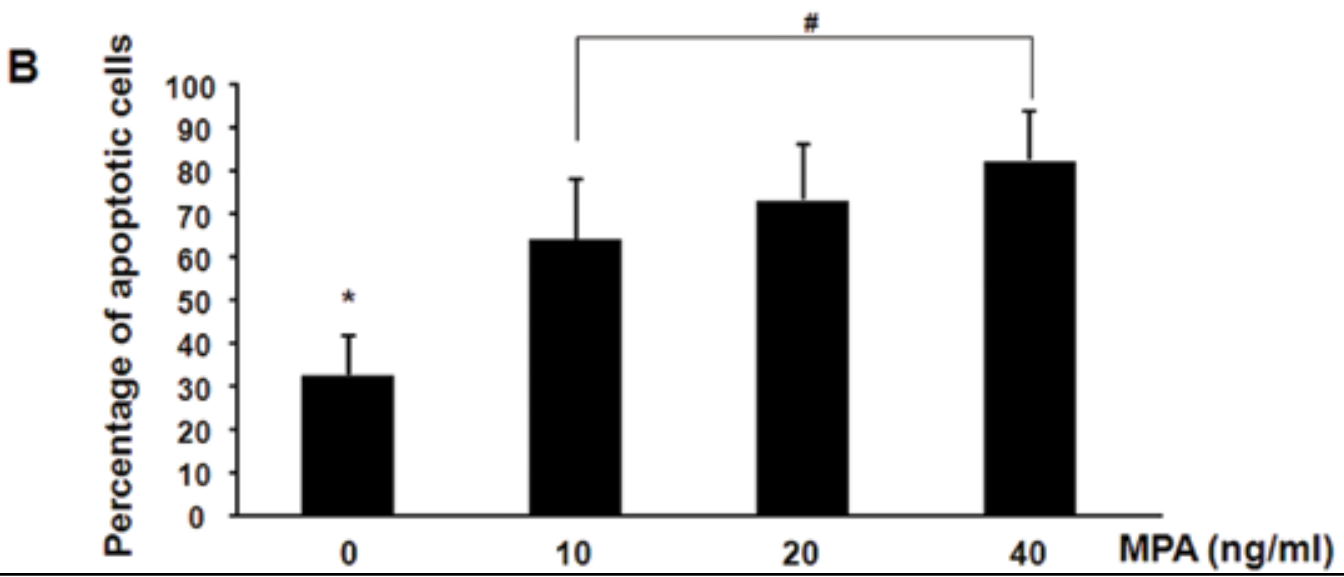

Fig. 1. TUNEL stained DRG sensory neurons exposed to different concentrations of MPA. Rat sensory DRG neurons exposed to different concentrations of $M P A(0,10,20$, and $40 \mathrm{ng} / \mathrm{mL})$. A) showing representative TUNEL stained (green) neurons; B) Plots showing the average percentage of apoptotic cells (mean $\pm S D$ ) from 30 fields (experiments were performed 3 times with 10 fields from each cover slips), where * indicates significant difference between control (0 ng/mL) and other doses of MPA (10, 20, and $40 \mathrm{ng} / \mathrm{mL}$ ) based on ANOVA test, and \# indicates difference after post hoc analysis between 10 and $40 \mathrm{ng} / \mathrm{mL})(P<0.05)$.

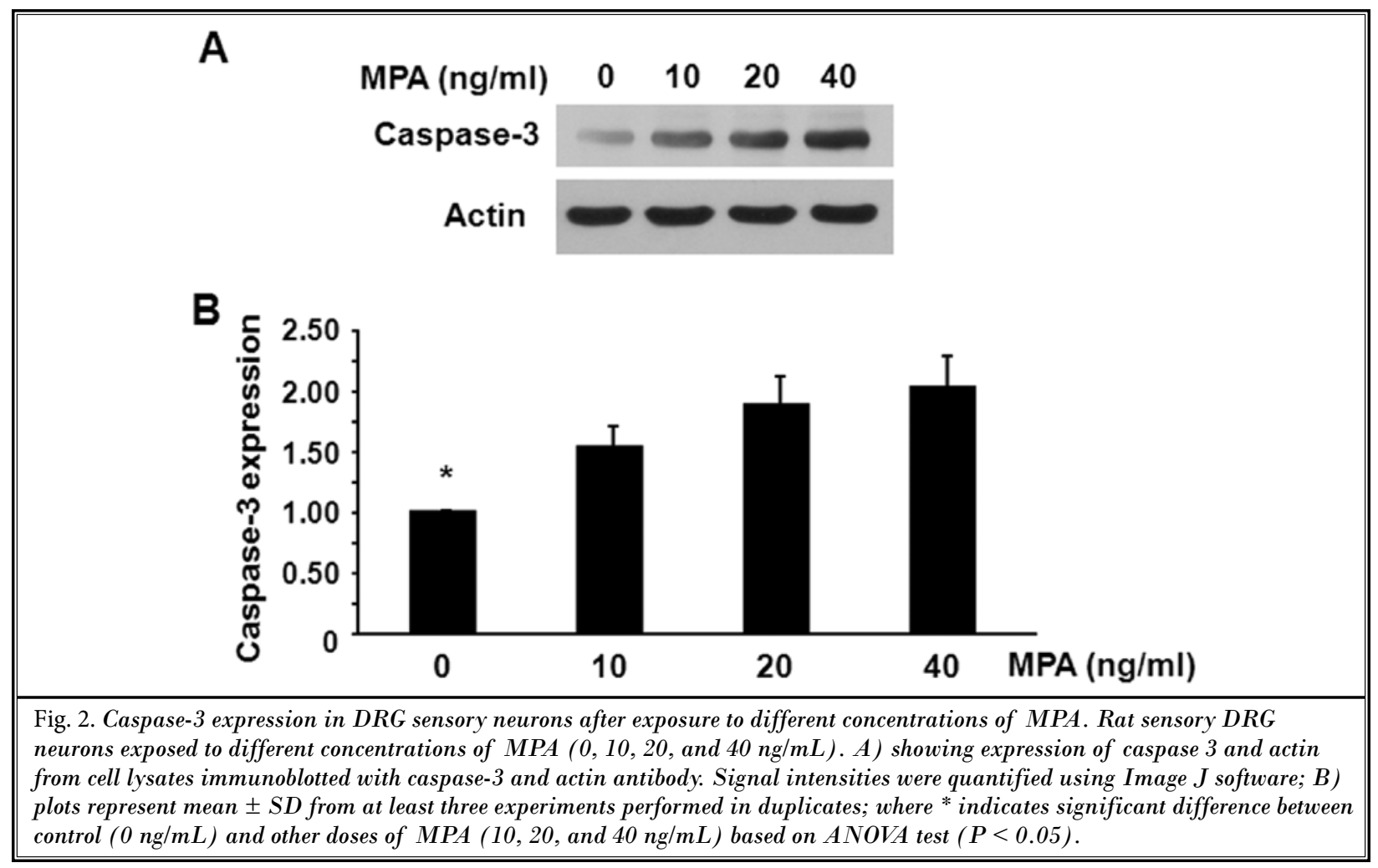




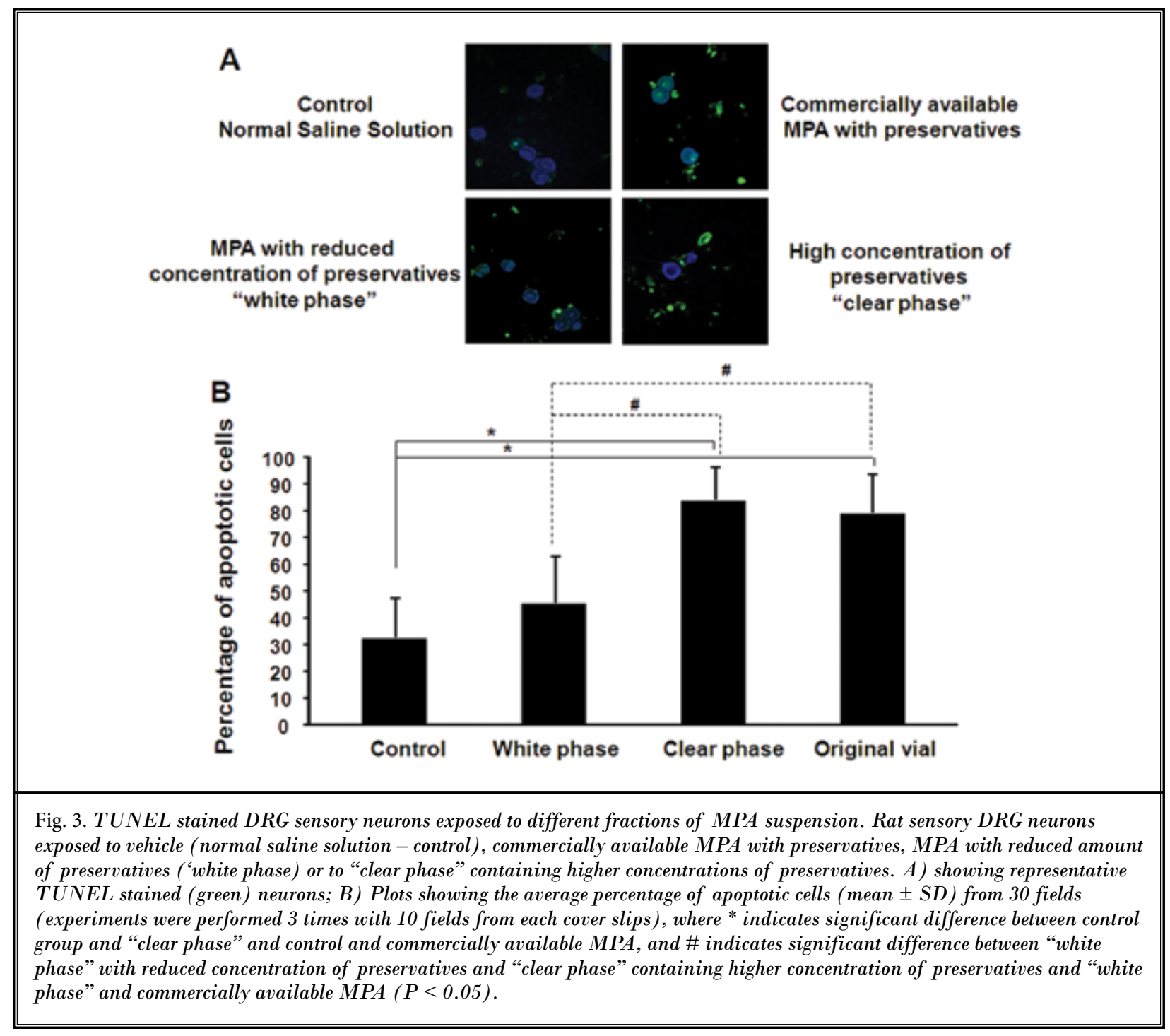

to MPA from the original vial or "clear phase" that contain higher concentrations of preservatives. Even though, MPA with reduced preservatives caused $12.5 \%$ more apoptosis in DRG sensory neurons than control, saline-treated cells (Fig. 3B), post hoc analysis showed no difference between these 2 groups. However, exposure of these neurons to MPA with intact preservatives (from the original commercially available vial) or to "clear phase" containing higher concentrations of preservatives caused about 50\% more deoxynucleotidyl transferase dUTP nick-end labeling (TUNEL) stained apoptotic cells (TUNEL positive cells) than in control ( $P$ $<0.0001$ ) (Fig. 3B).

Caspase-3 expression showed similar results (Fig. 4 A, B). Caspase-3 expression was slightly increased in neurons exposed to MPA with reduced preservatives, but the difference was not statistically significant $(P>$ 0.05). However, cells exposed to MPA from the original vial as well as "clear phase" containing mainly preservatives showed significantly higher expression of caspase-3 than control cells $(P<0.0001$ and $P=0.001$, respectively) and significantly higher expression than cells exposed to "white phase" containing MPA with reduced concentration of preservatives $(P=0.001$ and $P$ $=0.003$, respectively).

\section{Discussion}

Despite the fact that epidural MPA injections are commonly used as standard treatments in interventional pain management practices, IT MPA administration 


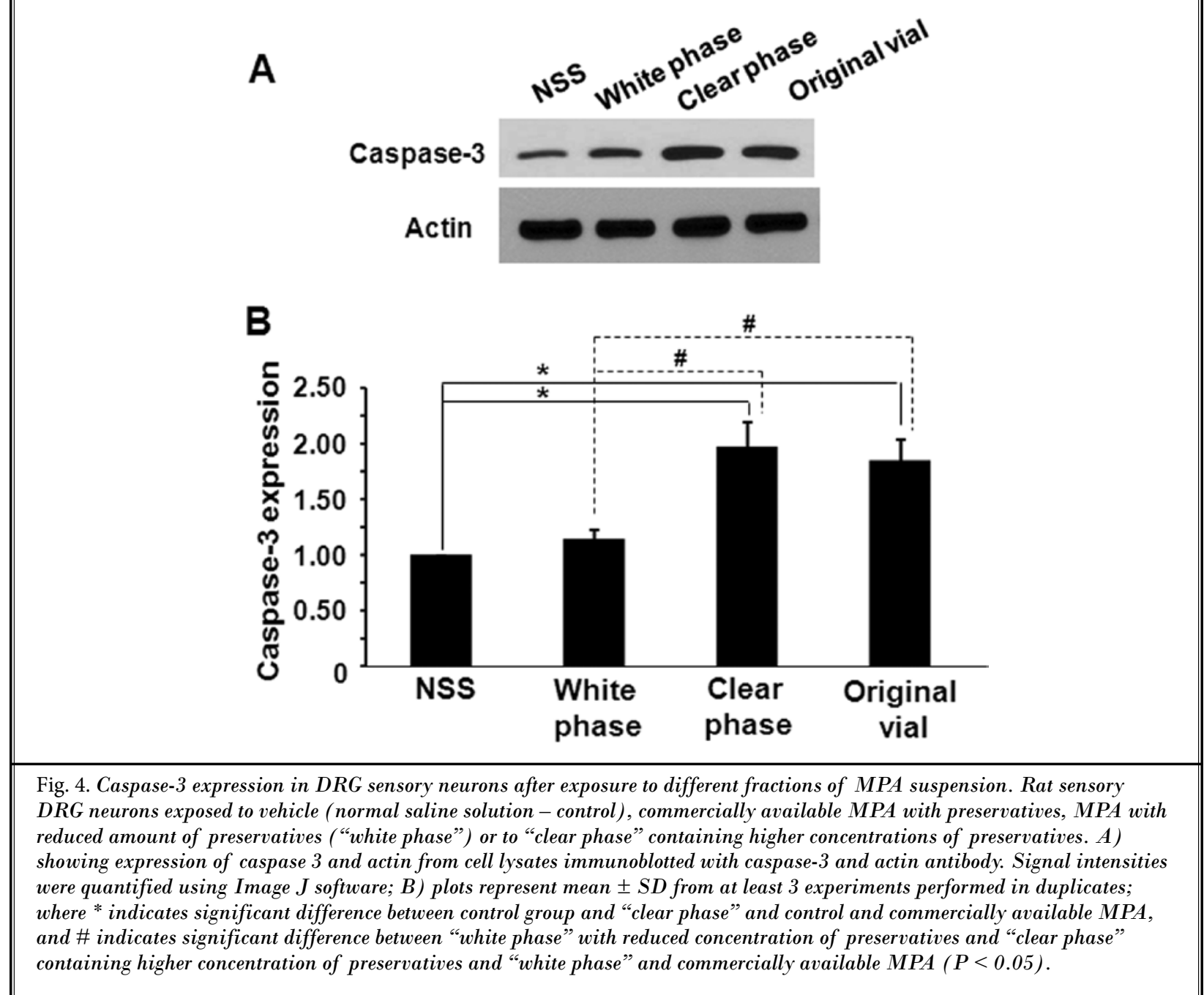

remains controversial. Even though, the IT administration of MPA has been found to be very effective in treatment of postherpetic neuralgia (22-25), repeated administration of MPA by this route has also been associated with numerous neurological complications (26-31). The issue of the safety of IT steroid therapy has been a controversial subject for several decades. Adverse events occurring following IT steroid application have implicated the presence of preservative additives (benzyl alcohol, benzalkonium chloride, MGPC, or PEG). Neuraxial injections of MPA with preservatives have occasionally been associated with chemical arachnoiditis, meningitis, transverse myelitis, etc., especially when injected intrathecally $(9,31,32)$.

The unanswered question is whether or not IT steroid administration results in damage to the neurons, meninges, and/or spinal cord (8,33-36). Zemel et al (37) showed that Depo-Medrol containing MGPC used periocularly in the treatment of ocular inflammation is highly toxic to the rabbit retina. Since the vertebrate retina is derived from an evagination of the diencephalon and developmentally is part of the central nervous system (CNS), this toxicity may be related to neurotoxicity as well (38). On the other side, Benzon et al (39) using an in vitro rabbit sheathed-nerve preparation found no significant changes in amplitude or conduction velocity with $3 \%$ PEG. Even $40 \%$ did not cause neurolysis in their study (39).

Results of the present study identified a cytotoxic effect of commercially available MPA with preservatives on primary isolated rat DRG sensory neurons shown by TUNEL positivity and caspase-3 expression. Caspase-3 
is one of the final executing caspase in the apoptotic pathways in DRG neurons $(20,21)$. Caspase-3, as an indicator of apoptosis, induces the proteolytic cleavage of many proteins that leads to cell death (40). Our results showed no statistically significant difference between the control cells (saline-treated) and cells treated with MPA with reduced concentrations of preservatives. However, cells treated with commercially available MPA or with a "clear phase" containing higher concentrations of preservatives showed statistically significant cytotoxic effect by TUNEL staining and caspase-3 expression. In our previous study (14) we measured only concentrations of MPA and PEG, but according to Rijsdijk et al (15) our separation should remove MGPC as well. Thus, results of this study are confirmatory that either PEG or MGPC, or their combination, has a harmful effect on the rat DRG sensory neurons. Similar results are expected with $40 \mathrm{mg} / \mathrm{mL}$ vials, since they contain almost the same concentrations of PEG and MGPC as $80 \mathrm{mg} / \mathrm{mL}$ vials.

Marinangeli et al (36) believed that steroid neurotoxicity is related to the addition of PEG and suggested that less concentrated PEG, diluted with local anesthetics and/or saline, might reduce the potential for neurotoxicity. In everyday practice, commercially available MPA is often diluted with normal saline and/or local anesthetics prior to injection into the epidural space, even though glucocorticoid manufacturers do not advocate for diluting or mixing MPA due to possible physical incompatibility (9). Furthermore local anesthetics per se may be neurotoxic (41) and may cause hemodynamic derangements or sensory and motor block, depending upon dose administered and route of administration. Mixing these components can increase the osmolality in the epidural space and can potentially cause neurotoxicity as well (9). Exposure of DRG sensory neurons to different concentrations of commercially available MPA in our study showed increased numbers of TUNEL positive cells and higher caspase-3 expression with increased concentrations. However, differences between adjacent doses were not statistically significant.

While Byrod et al (42) showed rapid venous transport of Evans-blue labeled albumin from the epidural space to spinal nerve roots and spinal nerves, indicating potentially fast transport of corticosteroids injected epidurally, these injections are largely considered to be safer than IT injections. Delaney et al (35) in a feline study of epidural injections of triamcinolone diacetate containing $3 \%$ of PEG and $0.9 \%$ of benzyl alcohol in 48 cats found only mild histological changes and con- cluded that this combination does not significantly damage neural tissue. Ten years later Cicala et al (34) compared injections of Depo-Medrol $(2 \mathrm{mg} / \mathrm{kg})$ and preservative-free $1 \%$ lidocaine $(0.3 \mathrm{mg} / \mathrm{kg})$ with $\mathrm{pH}$ balanced lactated Ringer's solution $(0.3 \mathrm{~mL} / \mathrm{kg})$ injected into a rabbit's epidural space. They found no signs of neurotoxicity 10 days after injection and no difference between Depo-Medrol and lactated Ringer's solution (34). Triamcinolone acetonide (Kenalog ${ }^{\circledR}$ ) and dexamethasone sodium phosphate (Decadron $®$ ) are free of PEG, but they contain $1 \%$ benzyl alcohol that has been shown to cause retinal toxicity in rabbits $(43,44)$ and flaccid paralysis after injecting saline solution that contained $1.5 \%$ benzyl alcohol (45). There are no studies showing how to reduce the concentration of benzyl alcohol or any studies that compare toxicity of PEG and benzyl alcohol.

Rijsdijk et al (15) showed that levels of MPA in the plasma remained detectable for up to 3 weeks following a fourth IT injection. Following treatment, all of the experimental dogs included in their study had normal laboratory results (complete blood counts, liver and kidney function). They observed only transient elevation of cell count and protein levels in the cerebrospinal fluid. In that study, animals were sacrificed 6 weeks after the last IT injection, and were subjected to postmortem examinations, where focal aggregates of activated microglia were observed along with mild inflammation in the spinal cord, but without evidence of neuronal injury or demyelination in adjacent nerve roots (15).

Rijsdijk et al (15) discussed potential direct toxic effect of MPA on the spinal cord; however no signs of transverse myelitis, sterile meningitis, or arachnoiditis were observed among the animals treated IT with MPA without preservatives. Furthermore, both Rijsdijk et al's study (15) and our current study used MPA with reduced preservatives. There is a chance that even small concentrations of preservatives caused the inflammatory reactions after IT injection of MPA in dogs (15), since we also had increased cytotoxicity in DRG neurons that was not statistically significant after using MPA with reduced concentrations of preservatives. Even though we are not advocating for the routine use of the IT injection of corticosteroids, there is no study showing a direct toxic effect of MPA on the spinal cord when used alone. The lack of evidence for MPA toxicity makes at least epidural steroid injections, and potentially subarachnoid exposure in cases of unintentional dural puncture that may occur during epidural steroid injections (14), safe, especially when used with reduced concentrations of 
preservatives. However, neither Rijsdijk et al (15) nor we tested the effects of MPA alone, because that would have required the use of compounded or purified MPA which was outside the scope of our manuscripts. Our results in conjunction with their results do suggest the importance of distinguishing between the indirect and direct neurotoxic effects of corticosteroids on the spinal cord, wherein preservatives may induce indirect microglia-mediated cytotoxicity in instances where the concentration of preservatives is not significantly reduced.

\section{Limitations}

Our presented study has several limitations. In the first place, our data were collected from in vitro isolated rat DRG neurons. There is a possibility that in vivo neurons have different extents of vulnerability compared to isolated neurons. Just as Benzon et al's (39) work on isolated rabbit sciatic nerves exposed to concentrations of PEG up to $40 \%$ is interpreted cautiously by neuraxial steroid advocates, our present work is reliable from the standpoint of the limitations imposed by using animal models in vitro to express concerns regarding human neuraxial exposure to glucocorticoid suspensions used in pain management.

\section{Conclusions}

Reduction of concentrations of preservatives from commercially available MPA suspensions by using the simple method of inverting vials for 2 hours could be considered useful in clinical practice to enhance the safety of this depot steroid when injected neuraxially.
Nevertheless, this method may prove to be an alternative to using compounded MPA, at least for instances wherein the use of compounding is being undertaken to provide MPA without preservatives. The fact that apoptosis occurred even with a reduction in concentrations of PEG and MGPC may stimulate additional research into finding methodologies to further reduce their respective concentrations prior to the use of these steroids in individuals for whom neuraxial injection is clinically indicated.

\section{Author Affiliations}

Dr. NN Knezevic is Director of Anesthesiology Research and Clinical Assistant Professor with the Department of Anesthesiology, Advocate Illinois Masonic Medical Center, Chicago, IL and Department of Anesthesiology, University of Illinois, Chicago, IL. Dr. Candido is Chairman and Professor of the Department of Anesthesiology, Advocate Illinois Masonic Medical Center, Chicago, IL, and Department of Anesthesiology, University of Illinois, Chicago, IL. Dr. Cokic is Project Scientist, Biomedical Imaging Research Institute, CedarsSinai Medical Center, Los Angeles, CA. Dr. Krbanjevic is Postdoctoral Research Associate, Department of Pharmacology, University of Illinois, Chicago, IL. Ms. Berth is $\mathrm{MD}, \mathrm{PhD}$ student with the Department of Anatomy and Cell Biology, University of Illinois, Chicago, IL. Dr. I. Knezevic is a Postdoctoral Research Associate with the Department of Physiology and Biophysics, University of Illinois, Chicago, IL and Clinical Research Coordinator, Department of Anesthesiology, Advocate Illinois Masonic Medical Center, Chicago, IL.

\section{References}

1. Brown JH. Pressure caudal anesthesia and back manipulation. Conservative method for treatment of sciatica. Northwest Med 1960; 59:905-909.

2. Winnie AP, Hartman JT, Meyers HL, Jr., Ramamurthy S, Barangan V. Pain clinic. II. Intradural and extradural corticosteroids for sciatica. Anesth Analg 1972; 51:990-1003.

3. Manchikanti L, Falco FJ, Singh V, Pampati V, Parr AT, Benyamin RM, Fellows $B$, Hirsch JA. Utilization of interventional techniques in managing chronic pain in the Medicare population: Analysis of growth patterns from 2000 to 2011. Pain Physician 2012; 15:E969-E982.

4. Cohen SP, Bicket MC, Jamison D, Wilkinson I, Rathmell JP. Epidural steroids: A comprehensive, evidencebased review. Reg Anesth Pain Med 2013; 38:175-200.

5. Manchikanti L, Pampati V, Boswell MV, Smith HS, Hirsch JA. Analysis of the growth of epidural injections and costs in the Medicare population: A comparative evaluation of 1997, 2002, and 2006 data. Pain Physician 2010; 13:199-212.

6. Friedly J, Chan L, Deyo R. Increases in lumbosacral injections in the Medicare population: 1994 to 2001. Spine (Phila Pa 1976) 2007; 32:1754-176o.

7. Samanta A, Samanta J. Is epidural injection of steroids effective for low back pain? BMJ 2004; 328:1509-1510.

8. Hodgson PS, Neal JM, Pollock JE, Liu SS. The neurotoxicity of drugs given in- trathecally (spinal). Anesth Analg 1999; 88:797-809.

9. Nelson DA, Landau WM. Intraspinal steroids: History, efficacy, accidentality, and controversy with review of United States Food and Drug Administration reports. J Neurol Neurosurg Psychiatry 2001; 70:433-443.

10. Winnie AP. Methylprednisolone acetate suspension (without benzyl alcohol). Reg Anesth 1991; 16:301.

11. Pettit AC, Kropski JA, Castilho JL, Schmitz JE, Rauch CA, Mobley BC, Wang XJ, Spires SS, Pugh ME. The index case for the fungal meningitis outbreak in the United States. N Engl J Med 2012; 367:2119-2125

12. Wilson LE, Blythe D, Sharfstein JM. 
Fungal meningitis from injection of contaminated steroids: A compounding problem. JAMA 2012; 308:2461-2462.

13. Centers for Disease Control and Prevention (CDC). Multistate Fungal Meningitis Outbreak Investigation. Available at: www.cdc.gov/HAl/outbreaks/meningitis.html. Accessed October 23, 2013.

14. Candido KD, Knezevic I, Mukalel J, Knezevic NN. Enhancing the relative safety of intentional or unintentional intrathecal methylprednisolone administration by removing polyethylene glycol. Anesth Analg 2011; 113:1487-1489.

15. Rijsdijk M, van Wijck AJ, Kalkman CJ, Meulenhoff PC, Grafe MR, Steinauer J, Yaksh TL. Safety assessment and pharmacokinetics of intrathecal methylprednisolone acetate in dogs. Anesthesiology 2012; 116:170-181.

16. Owen DE, Egerton J. Culture of dissociated sensory neurons from dorsal root ganglia of postnatal and adult rats. Methods Mol Biol 2012; 846:179-187.

17. Roy ML, Narahashi T. Differential properties of tetrodotoxin-sensitive and tetrodotoxin-resistant sodium channels in rat dorsal root ganglion neurons. J Neurosci 1992; 12:2104-2111.

18. Vega-Avelaira D, McKelvey R, Hathway $G$, Fitzgerald $M$. The emergence of adolescent onset pain hypersensitivity following neonatal nerve injury. Mol Pain 2012; 8:30.

19. Huang WL, Yang Q, Ward RE, Priestley JV. Hypoxia-induced apoptosis in adult rat dorsal root ganglion neurons in vitro. Neuroreport 2005; 16:89-93.

20. Schmeichel AM, Schmelzer JD, Low PA. Oxidative injury and apoptosis of dorsal root ganglion neurons in chronic experimental diabetic neuropathy. Diabetes 2003; 52:165-171.

21. Kamiya H, Zhangm W, Sima AA. Apoptotic stress is counterbalanced by survival elements preventing programmed cell death of dorsal root ganglions in subacute type 1 diabetic BB/Wor rats. Diabetes 2005; 54:3288-3295.

22. Kikuchi A, Kotani N, Sato T, Takamura K, Sakai I, Matsuki A. Comparative therapeutic evaluation of intrathecal versus epidural methylprednisolone for longterm analgesia in patients with intractable postherpetic neuralgia. Reg Anesth
Pain Med 1999; 24:287-293.

23. Kotani $\mathrm{N}$, Kushikata $\mathrm{T}$, Hashimoto $\mathrm{H}$, Kimura F, Muraoka M, Yodono M, Asai M, Matsuki A. Intrathecal methylprednisolone for intractable postherpetic neuralgia. $N$ Engl J Med 2000; 343:1514-1519.

24. Alper BS, Lewis PR. Treatment of postherpetic neuralgia: A systematic review of the literature. ] Fam Pract 2002; 51:121-128.

25. Candido KD, Mukalel JJ, Puppala VK, Knezevic NN. Management of postherpetic neuralgia with intrathecal methylprednisolone. Int Anesthesiol Clin 2011; 49:88-92.

26. Bernat JL, Sadowsky CH, Vincent FM, Nordgren RE, Margolis G. Sclerosing spinal pachymeningitis. A complication of intrathecal administration of depomedrol for multiple sclerosis. ] Neurol Neurosurg Psychiatry 1976; 39:1124-1128.

27. Nelson DA. Dangers from methylprednisolone acetate therapy by intraspinal injection. Arch Neurol 1988; 45:804-806.

28. Nelson DA. Intraspinal therapy using methylprednisolone acetate. Twentythree years of clinical controversy. Spine (Phila Pa 1976) 1993; 18:278-286.

29. Nelson DA, Landau WM. Intrathecal methylprednisolone for postherpetic neuralgia. N Engl J Med 2001; 344:1019.

30. Mackinnon SE, Hudson AR, Gentili F, Kline DG, Hunter D. Peripheral nerve injection injury with steroid agents. Plast Reconstr Surg 1982; 69:482-490.

31. Hurst EW. Adhesive arachnoiditis and vascular blockage caused by detergents and other chemical irritants: An experimental study. J Pathol Bacteriol 1955; 70:167-178.

32. Abram SE. Intrathecal steroid injection for postherpetic neuralgia: What are the risks? Reg Anesth Pain Med 1999; 24:283-285.

33. Hahn AF, Feasby TE, Gilbert JJ. Paraparesis following intrathecal chemotherapy. Neurology 1983; 33:1032-1038.

34. Cicala RS, Turner R, Moran E, Henley R, Wong R, Evans J. Methylprednisolone acetate does not cause inflammatory changes in the epidural space. Anesthesiology 1990; 72:556-558.
35. Delaney TJ, Rowlingson JC, Carron H, Butler A. Epidural steroid effects on nerves and meninges. Anesth Analg 1980; 59:610-614.

36. Marinangeli F, Ciccozzi A, Donatelli F, Paladini A, Varrassi G. (Clinical use of spinal or epidural steroids). Minerva Anestesiol 2002; 68:613-620.

37. Zemel E, Loewenstein A, Lazar M, Perlman I. The effects of myristyl gammapicolinium chloride on the rabbit retina: Morphologic observations. Invest Ophthalmol Vis Sci 1993; 34:2360-2366

38. Muranishi Y, Terada K, Furukawa T. An essential role for Rax in retina and neuroendocrine system development. Dev Growth Differ 2012; 54:341-348.

39. Benzon HT, Gissen AJ, Strichartz GR, Avram MJ, Covino BG. The effect of polyethylene glycol on mammalian nerve impulses. Anesth Analg 1987; 66:553-559.

40. Choi DK, Leem JG, Shin JW, Suh JH. Effects of ethyl pyruvate on allodynia, TNF-alpha expression, and apoptosis in the dorsal root ganglion after spinal nerve ligation injury. Korean J Pain 2012; 25:213-220.

41. Freedman JM, Li DK, Drasner K, Jaskela MC, Larsen B, Wi S. Transient neurologic symptoms after spinal anesthesia: An epidemiologic study of 1,863 patients. Anesthesiology 1998; 89:633-641.

42. Byrod G, Olmarker K, Konno S, Larsson K, Takahashi K, Rydevik B. A rapid transport route between the epidural space and the intraneural capillaries of the nerve roots. Spine (Phila Pa 1976) 1995; 20:138-143.

43. Morrison, VL, Koh HJ, Cheng L, Bessho K, Davidson MC, Freeman WR. Intravitreal toxicity of the kenalog vehicle (benzyl alcohol) in rabbits. Retina 2006; 26:339-344.

44. Macky TA, Helmy D, El Shazly N. Retinal toxicity of triamcinolone's vehicle (benzyl alcohol): An electrophysiologic and electron microscopic study. Graefes Arch Clin Exp Ophthalmol 2007; 245:817-824.

45. Craig, DB, Habib GG. Flaccid paraparesis following obstetrical epidural anesthesia: Possible role of benzyl alcohol. Anesth Analg 1977; 56:219-221. 